\title{
PENGARUH PENETAPAN JAM KERJA, PEMBERIAN INSENTIF DAN PENYELESAIAN KONFLIK DENGAN STRATEGI KOMPROMI TERHADAP PENGINGKATAN PRODUKTIVITAS KARYAWAN SHOFA MARWAH GROUP BOYOLALI TAHUN 2019
}

\author{
Danissa Agustin ${ }^{1)}$, Unna Ria Safitri ${ }^{2)}$, dan Listyowati Puji Rahayu ${ }^{3)}$ \\ ${ }^{1)}$ Program Studi Manajemen Fakultas Ekonomi Universitas Boyolali \\ Jl. Pandanaran 405, Telp. 0276321328 Boyolali \\ ${ }^{2}$ Fakultas Ekonomi Universitas Boyolali \\ Jl. Pandanaran 405, Telp. 0276321328 Boyolali \\ ${ }^{3)}$ Fakultas Ekonomi Universitas Boyolali \\ Jl. Pandanaran 405, Telp. 0276321328 Boyolali
}

e-mail: $\underline{\text { danissaagustin7@gmail.com }}{ }^{1)}, \underline{\text { unnaria68@gmail.com }}{ }^{2)}$, listyowatipujirahayu63@ gmail.com $^{3)}$

\begin{abstract}
ABSTRAK
Pada dunia modern yang menuntut perusahaan memiliki sumber daya manusia (SDM) agar dapat di kelola dengan srategi agar tercapai secara optimal, maka penulis melakukan penelitian yang berhubungan dengan tingkat produktivitas karyawan pada sebuah perusahaan di Boyolali yang membidangi beberapa usaha di bebebrapa sektor usaha yang berbeda ${ }^{1}$. Penelitian ini bertujuan untuk mengetahui dan membuktikan adanya pengaruh antara jam kerja, insentif, dan kompromi terhadap produktivitas karyawan Shofa Marwah Group Boyolali ${ }^{2}$.

Penelitian ini menggunakan metode kuantitatif dengan teknik pengumpulan data melalui kuesioner dan studi dokumen ${ }^{3}$. Dengan populasi 132 karyawan, sampel pada data ini adalah 100 responden karyawan Shofa Marwah Group Boyolali. Teknik analisis data yang digunakan adalah regresi linear berganda dengan menggunakan SPSS $22^{4}$.

Hasil penelitian ini dapat diambil kesimpulan bahwa jam kerja, insentif dan kompromi berpengaruh positif dan signifikan secara simultan terhadap produktivitas karyawan ${ }^{5}$. Namun hanya jam kerja yang berpengaruh positif dan signifikan secara parsial terhadap produktivitas karyawan.

Kata kunci : produktivitas, jam kerja, insentif, kompromi
\end{abstract}

\section{ABSTRACT}

In the modern world that requires companies to have human resources that can be managed properly so that company goals can be achieved optimally, the authors conducted research related to the level of employee productivity at a company in Boyolali which is in charge of several businesses in several different business sectors ${ }^{6}$. This study aims to determine and prove the influence of working hours, incentives, and compromise on employee productivity of Shofa Marwah Group Boyolali.

This research uses quantitative methods with data collection techniques through questionnaires and document studies. With a population of 132 employees, the sample in this data is 100 respondents of

\footnotetext{
${ }^{1}$ MASYRUUFAH SUGIONO and SUCI ROHAYATI,"Pengaruh Penggunaan Bahan Ajar E-Book Interaktif, Pemahaman Analisis Transaksi Dan Intensitas Latihan Soal Terhadap Hasil Belajar Siswa Pada Materi Jurnal Khusus Akuntansi Perusahaan Dagang Kelas Xi Smk Negeri 2 Buduran Sidoarjo",Jurnal Pendidikan Akuntansi (JPAK), 5.3 (2017), 1-7.

${ }^{2}$ Wili Andri Merdian,"Analisis Pengaruh Kualitas Pelayanan Terhadap Kepuasan Pelanggan (Studi Kasus TIKI, JI Mantrigawen Lor No 12 Yogyakarta)",Skripsi, 12, 2007, 126.

${ }^{3}$ Merdian.

${ }^{4}$ Annie goleman, daniel; boyatzis, Richard; Mckee and others, 'MONETER JURNAL AKUNTANSI DAN KEUANGAN VOLUME 7', "Journal of Chemical Information and Modeling", 53.9 (2013), 1689-99 < https://doi.org/10.1017/CBO9781107415324.004 >. 5 goleman, daniel; boyatzis, Richard; Mckee and others. ${ }^{6}$ Merdian.
} 
employees of the Boyolali Shofa Marwah Group.The data analysist techniques used is multiple linear regresion using SPSS $22^{7}$.

The result of thits study can be concluded $t$ working hours, incentives and compromise have a positive and significant effect simultaneously on employee productivity. However, only working hours have a positive and partially significant effect on employee productivity ${ }^{8}$.

Keywords: productivity, working hours, incentives, compromise

\footnotetext{
${ }^{7}$ goleman, daniel; boyatzis, Richard; Mckee and others. 8 goleman, daniel; boyatzis, Richard; Mckee and others.
} 


\section{Pendahuluan}

\section{Latar Belakang Masalah}

Di era ekonomi modern saat ini, sudah banyak terdapat perusahaan-perusahaan nasional yang memiliki banyak cabang usaha dibanyak bidang yang berbeda. Perusahaan dengan manajemen yang baik dapat mengelola banyak bidang usaha dalam satu pimpinan manajemen dengan produktivitas yang optimal. Sumber daya alam dan sumber daya manusia merupakan hal paling penting dalam mengelola perusahaan. Sumber daya alam yang di maksud adalah sumber bahan baku produksi yang terjamin ketersediaannya dan masih banyak hal lain yang menyangkut sumber daya alam lain dalam perusahaan ${ }^{9}$. Kemudian kualitas sumber daya manusia juga sangat berpengaruh untuk peningkatan produktivitas perusahaan ${ }^{10}$, misalnya dengan karyawan yg ahli pada bidang produksi, maka hasil produksi akan optimal. Penunjang peningkatan produktivitas karyawan selain mengelola SDM-nya, juga dengan beberapa cara lain yang menyangkut penghasilan karyawan yakni dengan insentif atas prestasi karyawan dan juga pengelolaan konfilk yang sesuai.

Ketika menjalankan perusahaan, manajemen perlu menetapkan kebijakan yang tepat untuk seluruh karyawan yang merupakan sumber daya manusianya. Dari beberapa divisi maka memerlukan kebijakan sesuai dengan fungsi masing-masing divisi. Pada beberapa divisi perusahaan menetapkan jam kerja dengan memertimbangkan peraturan pemerintah, kebutuhan hasil produksi, jumlah karyawan, kapasitas produksi dan kebutuhan pasar agar dapat sesuai dengan hasil kerja yang di targetkan. Namun ada beberapa perusahaan yang menetapkan jam kerja hanya dengan pertimbangan mengejar target produksi tanpa menghitung kapasitas produksi dan karyawan yang tersedia. Setiapkaryawan memiliki tugas yang berbeda sesuai dengan divisi masing-masing. Untuk memotivasi peningkatan produktivitas karyawan, perusahaan akan memberikan tambahan penghasilan dari prestasi karyawan yang disebut dengan insentif sesuai kapasitas kerjanya. Namun dalam beberapa kasus, masih terdapat sedikit kesenjangan dalam pemberian insentif kepada karyawan walaupun perusahaan memiliki pertimbangan sendiri dalam pemberian insentif.

Perusahaan akandapat meningkatkan produktivitas karyawan jika sumber daya manusianya tidak mengalami konflik dan berakibat pada pengunduran diri karyawan. Perusahaan akan menerapkan manajemen konflik yang sesuai dengan kebutuhan perusahaannya. Dengan pertimbangan adat istiadat, kebiasaan dan lingkungan maka perusahaan akan dengan mudah menerapkan strategi penyelesaian konflik yang sesuai. Yakni menerapkan strategi penyelesaian konflik dengan strategi kompromi.

\section{Rumusan masalah}

Rumusan masalah dalam penelitian ini adalah sebagai berikut:

1. Apakah penetapan jam kerja, pemberian insentif dan penyelesaian konflik dengan strategi kompromi secara parsial berpengaruh terhadap peningkatan produktivitas karyawan Shofa Marwah Group Boyolali?

2. Apakah penetapan jam kerja, pemberian insentif dan penyelesaian konflik dengan strategi kompromi secara simultan berpengaruh terhadap peningkatan produktivitas karyawan Shofa Marwah Group Boyolali?

\section{Tujuan penelitian}

Tujuan dari penelitian ini adalah

\footnotetext{
${ }^{9}$ RUMINI TRI UTAMI, 'PENGARUH INSENTIF, MOTIVASI, DAN PRESTASI TERHADAP PRODUKTIVITAS KERJA KARYAWAN DI LAZNAS YATIM MANDIRI', "Journal of Chemical Information and Modeling", 53.9 (2019), 168999 <https://doi.org/10.1017/CBO9781107415324.004 >.

${ }^{10}$ YANDHI FERNANDO,"FAKTOR-FAKTOR YANG MEMPENGARUHI PENDAPATAN PEDAGANG KAKI LIMA (STUDI KASUS DI PASAR BESAR KOTA MALANG)",Skripsi Makassar Jurusan Ilmu Ekonomi Feb UNHAS. , 2016.
} 
1. Untuk mengetahui apakah faktor jam kerja, insentif dan penyelesaian konflik dengan strategi kompromi namun sanggat memengaruhi terhadap peningkatan produktivitas karyawan Shofa Marwah Group Boyolali

2. Untuk mengetahui apakah faktor jam kerja, insentif dan penyelesaian konflik dengan strategi kompromi secara simultan berpengaruh terhadap peningkatan produktivitas karyawan Shofa Marwah Group Boyolali. ${ }^{11}$

\section{Landasan Teori dan Pengembangan Hipotesis}

Pengertian manajemen sumber daya manusia menurut H. Malayu S.P Hasibuan (2017 : 10) adalah Ilmu dan seni mengatur hubungan dan peranan tenaga kerja agar efektif dan efisien membantu terwujudnya tujuan perusahaan, karyawan, dan masyarakat.

Menurut Basu Swasta dalam shinta (2009 : 47) mengatakan bahwa Produktivitas merupakan salah satu alat ukur bagi perusahaan dalam menilai prestasi kerja yang dicapai karyawannya.

Dalam pendapat Su'ud, (2007:132) jam kerja merupakan waktu secara umum bisa di gunakan siang maupun malam hari. Merencanakan sebuah pekerjaan agar dapat memperbaiki pengurusan waktu yang di lakukan.

Menurut Mangkunegara (2009:89) menyebutkam insentif adalah penghargaan dalam bentuk uang yang diberikan oleh pihak pemimpin organisasi kepada karyawan agar mereka bekerja dengan motivasi yang tinggi dan berprestasi dalam mencapai tujuan organisasi.

Menurut Faules dalam najib (2016 : 11) bahwa konflik merupakan ekspresi pertikaian antara individu dengan individu lain, kelompok dengan kelompok lain karena beberapa alasan. Salah satu strategi penyelesaian konflik adalah dengan kompromi.

Disini kesimpulan sementara adalah : H1 : jam kerja, pemberian insentif dan konflik dan kompromi pada karyawan shofa marwah boyolali sanggat berpengaruh secara dan produktif $^{12}$.

\section{Metode Penelitian}

Penelitian ini adalah penelitian kuantitatif ${ }^{13}$, teknik pengumpulan data yang digunakan adalah Angket (Kuesioner) dan studi dokumen, populasi yang digunakan merupakan 132 karyawan Shofa Marwah Group Boyolali dan sampel penelitian setelah digunakan hitung Slovin ditemukan hasil sebesar 100 karyawan sebagai responden, obyek penelitian merupakan karyawan shofa marwah group boyolali,

definisi operasional variabelJam kerja (X1) yang di terapkan di Shofa Marwah Group adalah menyesuaikan kebutuhan pelayanan konsumen masing-masing bidang usaha. Hampir disetiap bidang usaha menggunakan jam kerja senin sampai dengan sabtu pukul 08.00-16.00, libur hari minggu dan hari besar nasional. Khusus untuk restoran Terminal kepiting di berikan jam kerja lebih namun terdapat 2 shift kerja karyawan.

Pada pemberian insentif (X2) Shofa Marwah Group Boyolali menerapkan sistem prosentase pada setiap penjualan barang dagang. Setiap karyawan memiliki hak yang sama atas insentif pada penjualan barang dagang yang berhasil dia jual. Penjualan barang dagang tidak hanya tugas pokok sales saja, namun untuk semua karyawan yang bisa menjual barang dagang maka akan mendapatkan prosentase yang sama dari nilai jual barang dagang tersebut. Prosentase insentif penjualan sebesar 5-10\% dari nilai barang terjual sesuai kebijakan perusahaan.

\footnotetext{
${ }^{11}$ BUDI WAHYONO, 'ANALISIS FAKTOR-FAKTOR YANG MEMPENGARUHI PENDAPATAN PEDAGANG DI PASAR BANTUL KABUPATEN BANTUL', Jurnal Agribisnis, 11.6 (2017), 183-201.

${ }^{12}$ SUPRIYANTO dan TRI BODROASTUTI,"Faktor-Faktor Yang Mempengaruhi Produktivitas (Studi Pada Karyawan Bagian Produksi PT Nusantara Building Industries)", 2019, 1-14.

${ }^{13}$ NUR RAHMATIKA PERTIWI,"PENGARUH PROGRAM PUNISHMENT DAN REWARD DALAM MENINGKATKAN PRODUKTIVITAS KERJA PEGAWAI MENURUT PERSPEKTIF EKONOMI ISLAM (Studi Pada BPJS Ketenagakerjaan Bandar Lampung)", Jurnal Hospitality Dan Manajemen Jasa, 5 (2017), 390-400.
} 
Penyelesaian konflik dengan kompromi (X3) di Shofa Marwah Group dengan menggunakan strategi kompromi. Yakni masing-masing pihak berkonflik akan megutarakan pendapat atas masalah dan mencari solusi terbaik atas konflik tersebut. Konflik yang sering terjadi adalah konflik antara kebijakan perusahaan dengan kepentingan karyawan yang di anggap karyawan kurang tepat untuk mereka. Dengan strategi penyelesaian konflik berupa kompromi Shofa Marwah Group dapat menekan angka keluar masuk karyawan baru.

Produktivitas kerja karyawan Shofa Marwah Group menerapkan penilaian atas produktivitas karyawan dengan melihat hasil kerja karyawan, pencapaian kerja, peningkatan penguasaan pekerjaan di masing-masing divisi, respon inisiatif dan kreativitas karyawan, kerja sama antar karyawan dan antar divisi dalam bekerja. Metode analisis data dalam penelitian ini dengan analisis regresi berganda yakni untuk mengukur hubungan antara variabel dependen dan variabel independen ${ }^{14}$.

\section{Hasil dan Pembahasan}

\subsection{Uji Instrumen Penelitian}

\subsubsection{Uji Validitas}

Adapun penelitian oleh Shofa Marwah Group, melakukan sebuah penelitian dan pengambilan data 100 responden ${ }^{15}$. Kemudian uji validasi di lakukan agar dapat mengetahui butir pertanyaan yang di susun di dalam kuesioner kemudian akan di cek apa sudah benar atau masi salah agar mendapatakn responden dan hasil yang maksimal. Adapun uraian pengujian dapat di lihat pada tabel beriku.

Tabel 4.1Variabel Jam Kerja ( X1 )

\begin{tabular}{|c|c|c|c|c|}
\hline Variabel & Pernyataan & $\mathbf{r}_{\text {hitung }}$ & $r_{\text {tabel }}$ & Keterangan \\
\hline \multirow{10}{*}{$\operatorname{Jam} \operatorname{kerja}\left(\mathrm{X}_{1}\right)$} & Butir 1 & 0,517 & 0,165 & Valid \\
\hline & Butir 2 & 0,686 & 0,165 & Valid \\
\hline & Butir 3 & 0,741 & 0,165 & Valid \\
\hline & Butir 4 & 0,720 & 0,165 & Valid \\
\hline & Butir 5 & 0,589 & 0,165 & Valid \\
\hline & Butir 6 & 0,764 & 0,165 & Valid \\
\hline & Butir 7 & 0,646 & 0,165 & Valid \\
\hline & Butir 8 & 0,350 & 0,165 & Valid \\
\hline & Butir 9 & 0,837 & 0,165 & Valid \\
\hline & Butir 10 & 0,829 & 0,165 & Valid \\
\hline \multirow[t]{7}{*}{ Insentif $\left(X_{2}\right)$} & Butir 11 & 0,800 & 0,165 & Valid \\
\hline & Butir 12 & 0,796 & 0,165 & Valid \\
\hline & Butir 13 & 0,793 & 0,165 & Valid \\
\hline & Butir 14 & 0,810 & 0,165 & Valid \\
\hline & Butir 15 & 0,606 & 0,165 & Valid \\
\hline & Butir 16 & 0,758 & 0,165 & Valid \\
\hline & Butir 17 & 0,678 & 0,165 & Valid \\
\hline \multirow[t]{4}{*}{ Kompromi $\left(\mathrm{X}_{3}\right)$} & Butir 18 & 0,716 & 0,165 & Valid \\
\hline & Butir 19 & 0,578 & 0,165 & Valid \\
\hline & Butir 20 & 0,657 & 0,165 & Valid \\
\hline & Butir 21 & 0,519 & 0,165 & Valid \\
\hline
\end{tabular}

\footnotetext{
${ }^{14}$ goleman, daniel; boyatzis, Richard; Mckee and others.

${ }^{15}$ UTAMI.
} 


\begin{tabular}{|l|l|l|l|l|}
\hline \multirow{5}{*}{ Produktivitas (Y) } & Butir 22 & 0,761 & 0,165 & Valid \\
& Butir 23 & 0,668 & 0,165 & Valid \\
& Butir 24 & 0,822 & 0,165 & Valid \\
& Butir 25 & 0,749 & 0,165 & Valid \\
& Butir 26 & 0,729 & 0,165 & Valid \\
& Butir 27 & 0,653 & 0,165 & Valid \\
& Butir 28 & 0,725 & 0,165 & Valid \\
\hline
\end{tabular}

Sumber : Data Primer diolah, 2020

Dengan melihat tabel 4.1 diatas menunjukkan bahwa item-item pernyataan variabel produktivitas karyawan semua dinyatakan valid, karena $r_{\text {tabel }}<r_{\text {hitung }}$. Skor tertinggi $0.822\left(\mathrm{r}_{\text {hitung }}>0.165\left(\mathrm{r}_{\text {tabel }}\right)\right.$ menandakan bahwa butir 24 yaitu pernyataan "Saya selalu berusaha untuk meningkatkan mutu hasil pekerjaan dari waktu ke waktu" adalah indikator yang dominan membentuk respon terhadap produktivitas karyawan.

\subsubsection{Uji Reabilitas}

Dalam Uji reliabilitas ini peneliti akan mengukur agar kemudian dapat menemukan hasil dan bisa di percaya, dengan alat bantu computer yakni menggunakan program SPSS 22. Sehingga di dapat hasil yaitu sbb ${ }^{16}$ :

\section{Tabel 4.2Hasil Uji Reliabilitas}

\begin{tabular}{|c|c|c|c|}
\hline Variabel & Cronbach Alpha & $\begin{array}{c}\text { Standar Cronbach } \\
\text { Alpha }\end{array}$ & Keterangan \\
\hline Jam kerja $\left(\mathrm{X}_{1}\right)$ & 0,784 & 0,600 & Reliabel \\
Insentif $\left(\mathrm{X}_{2}\right)$ & 0,870 & 0,600 & Reliabel \\
Kompromi $\left(\mathrm{X}_{3}\right)$ & 0,723 & 0,600 & Reliabel \\
Produktivitas $(\mathrm{Y})$ & 0,844 & 0,600 & Reliabel \\
\hline
\end{tabular}

Sumber :Data Primer diolah, 2020.

Berdasar tabel 4.2 diatas diketahui bahwa item pernyataan dari variabel jam kerja dengan nilai Cronbach Alpha 0.784, insentif dengan nilai Cronbach Alpha 0.870, kompromi dengan nilai Cronbach Alpha 0.723 dan produktivitas dengan nilai Cronbach Alpha 0.844 dalam penelitian ini adalah reliabel ${ }^{17}$. Hal tersebut ditunjukan oleh nilai Cronbach Alpha > 0,600. Untuk mendukung penelitian ini maka di buatkan kuesioner ${ }^{18}$.

\subsection{Analisis Data}

\subsubsection{Uji Asumsi Klasik}

\subsubsection{Uji Normalitas}

Tabel 4.3 Uji Normalitas

One-Sample Kolmogorov-Smirnov Test

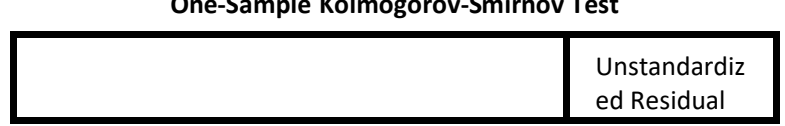

\footnotetext{
${ }^{16}$ UTAMI.

${ }^{17}$ UTAMI.

${ }^{18}$ UTAMI.
} 


\begin{tabular}{|ll|l|}
\hline $\mathrm{N}$ & & 100 \\
Normal Parameters $^{\mathrm{a}, \mathrm{b}}$ & Means & .0000000 \\
& Std. & 2.63689873 \\
& Deviation & \\
Most Extreme & Absolute & .055 \\
Differences & Positive & .055 \\
& Negative & -.052 \\
Test Statistic & & .055 \\
Asymp. Sig. (2-tailed) & & $.200^{\mathrm{c}, \mathrm{d}}$ \\
\hline
\end{tabular}

a.test di stribution normal.

b calculated from data.

c.lilliefors Significance correction.

d.this is a lower bound of the true significance.

Sumber : Data yang diolah, 2020

Dari tabel 4.3 nilai signifikan pada 0,200 yakni $>0,05$ ini berarti bahwa distribusi data produktivitas adalah berdistribusi normal.

\subsubsection{Uji Multikolinearitas}

\section{Tabel 4.9 Uji Multikolinearitas}

\begin{tabular}{|c|c|c|c|c|c|c|c|c|}
\hline \multicolumn{9}{|c|}{ Coefficients $^{a}$} \\
\hline & \multirow[b]{2}{*}{ Model } & \multicolumn{2}{|c|}{$\begin{array}{l}\text { Unstandardized } \\
\text { Coefficients }\end{array}$} & \multirow{2}{*}{$\begin{array}{c}\begin{array}{c}\text { Standardiz } \\
\text { ed } \\
\text { Coefficien } \\
\text { ts }\end{array} \\
\\
\text { Beta }\end{array}$} & \multirow[b]{2}{*}{$t$} & \multirow[b]{2}{*}{ Sig. } & \multicolumn{2}{|c|}{$\begin{array}{l}\text { Collinearity } \\
\text { Statistics }\end{array}$} \\
\hline & & B & $\begin{array}{l}\text { Std. } \\
\text { Error }\end{array}$ & & & & $\begin{array}{l}\text { Tolera } \\
\text { nce }\end{array}$ & VIF \\
\hline \multirow[t]{4}{*}{1} & (Constant) & $\begin{array}{r}11.04 \\
1\end{array}$ & 3.264 & & $\begin{array}{r}3.38 \\
3\end{array}$ & .001 & & \\
\hline & JAM KERJA & .491 & .085 & .540 & $\begin{array}{r}5.80 \\
6\end{array}$ & .000 & .782 & $\begin{array}{r}1.2 \\
79\end{array}$ \\
\hline & INSENTIF & .015 & .078 & 019 & .193 & .847 & .712 & $\begin{array}{r}1.4 \\
05\end{array}$ \\
\hline & $\begin{array}{l}\text { KOMPRO } \\
\text { MI }\end{array}$ & .146 & .113 & .116 & $\begin{array}{r}1.28 \\
5\end{array}$ & .202 & .829 & $\begin{array}{r}1.2 \\
07\end{array}$ \\
\hline
\end{tabular}

a. Dependent Variable: PRODUKTIFITAS

Sumber : Data yang diolah, 2020

Berdasarkan tabel 4.9 di temukanya multikolinearitas, di dapatkan nilai tolerance variabel jam kerja 0.782 , variabel insentif 0.712 , dan variabel kompromi 0.829 lebih dari 0,1 dan nilai VIF variabel jam kerja 1.279 , variabel insentif 1.405, dan variabel kompromi 1.207 tidak lebi 10. Sehingga pada penelitian ini tidak di gunakannya multikolinearitas pada variabel bebas didalam model regresi ${ }^{19}$.

\subsubsection{Uji Heterokedastisitas}

Tabel 4.10Uji Heterokedastisitas

Coefficients $^{\mathrm{a}}$

${ }^{19}$ FERNANDO. 


\begin{tabular}{|c|c|c|c|c|c|}
\hline \multirow[b]{2}{*}{ Model } & \multicolumn{2}{|c|}{ Unstandardized Coefficients } & \multirow{2}{*}{$\begin{array}{c}\begin{array}{c}\text { Standardized } \\
\text { Coefficients }\end{array} \\
\text { Beta }\end{array}$} & \multirow[b]{2}{*}{$\mathrm{t}$} & \multirow[b]{2}{*}{ Sig. } \\
\hline & $B$ & Std. Error & & & \\
\hline 1 (Constant) & .887 & 2.096 & & $\begin{array}{r}.42 \\
3\end{array}$ & $\begin{array}{r}.67 \\
3\end{array}$ \\
\hline JAM KERJA & .007 & .054 & 015 & $\begin{array}{r}.13 \\
1\end{array}$ & $\begin{array}{r}.18 \\
6\end{array}$ \\
\hline INSENTIF & .018 & .050 & .044 & $\begin{array}{r}.36 \\
7\end{array}$ & $\begin{array}{r}.00 \\
0\end{array}$ \\
\hline KOMPROMI & .013 & .073 & .020 & $\begin{array}{r}18 \\
1\end{array}$ & $\begin{array}{r}.26 \\
7\end{array}$ \\
\hline
\end{tabular}

Sumber : Data yang diolah, 2020

Hasil tampilan output SPSS 22 menunjukkan koefisien untuk variabel independen jam kerja, insentif dan kompromi mempunyai nilai signifikansi $0,673>0,05$, maka dapat disimpulkan bahwa model regresi dalam penelitian ini tidak terdapat gejala heterokedastisitas ${ }^{20}$.

\title{
4.2.1.4 Uji Autokorelasi
}

Pada pengujian ini model regresi linear bertujuan agar adanya korelasi antara suatu problem penggangu dalam waktu $t$ dengan problem pengganggu periode t-1 sebelumnya, namun jika di temukan sebuah korelasi maka di namakan kesalahan autokorelasi.

Tabel 4.11Uji Autokorelasi

\begin{tabular}{|c|c|r|r|r|r|}
\hline $\begin{array}{c}\text { Mod } \\
\mathrm{el}\end{array}$ & $\mathrm{R}$ & $\begin{array}{c}\mathrm{R} \\
\text { Square }\end{array}$ & $\begin{array}{c}\text { Adjusted R } \\
\text { Square }\end{array}$ & $\begin{array}{c}\text { Std. Error of } \\
\text { the Estimate }\end{array}$ & $\begin{array}{c}\text { Durbin- } \\
\text { Watson }\end{array}$ \\
\hline 1 & $\begin{array}{r}.592 \\
\mathrm{a}\end{array}$ & .351 & .331 & 2.678 & 2.474 \\
\hline
\end{tabular}

a Predictors: (Constant), KOMPROMI,JAM KERJA,INSENTIF

b.Dependent Variable: PRODUKTIFITAS

Sumber : Data yang diolah, 2020

Hasil dari analisis output SPSS 22 tabel 4.11 diatas menunjukkan besarnya nilai Durbin Watson sebesar 2,474. Dengan jumlah variabel independen tiga $(\mathrm{k}=3)$ dan jumlah sampel $100(\mathrm{n}=100)$ diperoleh nilai dl sebesar 1,613 dan dusebesar 1,736. Oleh karena nilai DW hitung $2.474>$ du 1.736, dan dengan menggunakan nilai signifikan 5\%, maka dapat disimpulkan tidak terjadi autokorelasi antar residual.

\subsubsection{Analisis Regresi}

\subsubsection{Analisis Regresi Berganda}

Dalam hal ini analisis regresi berganda di gunakan agar kemudian dapat mengetahui bagaimana pengaruh variabel jam kerja $X_{1}$ insentif $X_{2}$, dan kompromi $\mathrm{X}_{3}$ mengenai produktivitas pada variabel.

Berdasarkan pada hasil perhitungan diketahui persamaan garis regresi sbb :

\section{Tabel 4.21 Output Regresi Linier Berganda}

\author{
Coefficients $^{\mathrm{a}}$
}

\footnotetext{
${ }^{20}$ FERNANDO.
} 


\begin{tabular}{|c|c|c|c|c|c|c|}
\hline \multirow{2}{*}{\multicolumn{2}{|c|}{ Model }} & \multicolumn{2}{|c|}{ Unstandardized Coefficients } & \multirow{2}{*}{$\begin{array}{c}\begin{array}{c}\text { Standardized } \\
\text { Coefficients }\end{array} \\
\text { Beta }\end{array}$} & \multirow[b]{2}{*}{$\mathrm{T}$} & \multirow[b]{2}{*}{ Sig. } \\
\hline & & B & Std Error & & & \\
\hline \multicolumn{2}{|c|}{1 (Constant) } & 11.041 & 3.264 & & 3.383 & .001 \\
\hline & JAM KERJA & .491 & .085 & .540 & 5.806 & .000 \\
\hline & INSENTIF & 015 & 078 & 019 & 193 & 847 \\
\hline & KOMPROMI & 146 & .113 & .116 & 1.285 & .202 \\
\hline
\end{tabular}

a. Dependent Variable: PRODUKTIFITAS

Sumber : Data yang diolah, 2020

Persamaan regresi yang diperoleh dari perhitungan tersebut adalah sebagai berikut $^{21}$ :

$$
\begin{aligned}
& y=\alpha+b_{1} \cdot X_{1}+b_{2} \cdot X_{2}+b_{3} \cdot X_{3}+e \\
& y=11.041+0.491 X_{1}+0.015 X_{2}+0.146 X_{3}
\end{aligned}
$$

Di mana :

$\mathrm{y} \quad=$ Produktivitas karyawan.

a $\quad=$ Nilai Konstanta.

$\mathrm{x} \quad=$ Variabel jam kerja.

$\mathrm{x}=$ Variabel insentif

$\mathrm{x} \quad=$ Variabel kompromi.

3 y $=$ Produktivitas karyawan

e $\quad=$ error term (diabaikan).

Adapun persamaan pada regresi dapat di jelaskan bahwasanya konstanta yang di miliki sebesar 11.041 menjelaskan bahwa tidak adanya variabel jam kerja $\left(\mathrm{X}_{1}\right)$, variabel insentif $\left(\mathrm{X}_{2}\right)$ dan variabel kompromi $\left(\mathrm{X}_{3}\right)$ maka nilai produktivitas karyawan sebesar 11.041 satuan $^{22}$. Dari pernyataan diatas maka dapat disimpulkan bahwa model regresi cocok dipakai untuk memprediksi produktivitas karyawan, dimana :

\begin{tabular}{|l|l|}
\hline$\alpha=11.041$ & $\begin{array}{l}\text { Koefisien regresi jam kerja, insentif dan kompromi sama dengan nol, maka nilai } \\
\text { produktivitas sebesar 11.041 satuan. }\end{array}$ \\
\hline $\mathrm{X}_{1}=0.491$ & $\begin{array}{l}\text { Koefisien regresi jam kerja sebesar } 0.491 \text { berarti setiap terjadi kenaikan, nilai jam } \\
\text { kerja }\left(\mathrm{X}_{1}\right), \text { maka akan menaikkan nilai produktivitas (Y) sebesar 0.491. }\end{array}$ \\
\hline $\mathrm{X}_{2}=0.015$ & $\begin{array}{l}\text { Koefisien regresi insentif sebesar 0.015 berarti setiap terjadi kenaikan, nilai insentif } \\
\left(\mathrm{X}_{2}\right), \text { maka akan menaikkan nilai produktivitas (Y) sebesar 0.015. }\end{array}$ \\
\hline $\mathrm{X}_{3}=0.146$ & $\begin{array}{l}\text { Koefisien regresi kompromi sebesar 0.146 berarti setiap terjadi kenaikan, nilai } \\
\text { kompromi }\left(\mathrm{X}_{3}\right), \text { maka akan menaikkan nilai produktivitas (Y) sebesar 0.146. }\end{array}$ \\
\hline
\end{tabular}

\subsection{Pengujian Hipotesis \\ 4.3.1 Uji t}

Perumusan Hipotesis :

\footnotetext{
${ }^{21}$ WAHYONO.

${ }^{22}$ UTAMI.
} 
$H_{0}$ : variabel jam keja $X_{1}$, insentif $X_{2}$, dan kompromi $X_{3}$, parsial tidak memengaruhi produktivitas karyawan ${ }^{23}$.

$\mathrm{H}_{\mathrm{a}}$ : variabel jam kerja $\mathrm{X}_{1}$, insentif $\mathrm{X}_{2}$, kompromi $\mathrm{X}_{3}$ secara parsial berpengaruh pada produktivitas karyawan ${ }^{24}$.

\section{Tabel 4.13 tabel Uji T}

\begin{tabular}{|c|c|c|c|c|c|c|c|c|}
\hline \multicolumn{9}{|c|}{ Coefficients $^{\mathrm{a} .}$} \\
\hline & \multirow[b]{2}{*}{ Model } & \multicolumn{2}{|c|}{$\begin{array}{c}\text { Unstandardized } \\
\text { Coefficients }\end{array}$} & \multirow{2}{*}{$\begin{array}{c}\begin{array}{c}\text { Standardi } \\
\text { zed } \\
\text { Coefficien } \\
\text { ts }\end{array} \\
\text { Beta }\end{array}$} & \multirow[b]{2}{*}{ T } & \multirow[b]{2}{*}{ Sig. } & \multicolumn{2}{|c|}{$\begin{array}{l}\text { Collinearity } \\
\text { Statistics }\end{array}$} \\
\hline & & B & $\begin{array}{l}\text { Std } \\
\text { Error }\end{array}$ & & & & $\begin{array}{l}\text { Tolera } \\
\text { nce }\end{array}$ & VIF \\
\hline \multirow[t]{4}{*}{1} & (Constant) & $\begin{array}{r}11.04 \\
1\end{array}$ & 3.264 & & $\begin{array}{r}3.38 \\
3\end{array}$ & .001 & & \\
\hline & JAM KERJA & .491 & .085 & .540 & $\begin{array}{r}5.80 \\
6\end{array}$ & .000 & .782 & $\begin{array}{r}1.2 \\
79\end{array}$ \\
\hline & INSENTIF & .015 & .078 & .019 & .193 & .847 & .712 & $\begin{array}{r}1.4 \\
05\end{array}$ \\
\hline & $\begin{array}{l}\text { KOMPRO } \\
\text { MI }\end{array}$ & .146 & .113 & .116 & $\begin{array}{r}1.28 \\
5\end{array}$ & .202 & .829 & $\begin{array}{r}1.2 \\
07\end{array}$ \\
\hline
\end{tabular}

a. Dependent Variable: PRODUKTIFITAS

Sumber : Data yang diolah, 2020

Tabel 4.14 Hasil Uji t

\begin{tabular}{|l|c|c|c|}
\hline \multicolumn{1}{|c|}{ Variabel } & T & Sig & Keterangan \\
\hline Jam kerja & 5,806 &, 000 & Signifikan \\
\hline Insentif & 0.193 &, 847 & Tidak Signifikan \\
\hline Kompromi & 1,285 &, 202 & Tidak Signifikan \\
\hline
\end{tabular}

Sumber : Data yang diolah, 2020

\section{Pembahasan :}

1. Analisis terhadap variabel jam kerja

Untuk variabel jam kerja, apabila Sig. 0,00>0,05 maka $\mathrm{H}_{\mathrm{o}}$ di terima dan $\mathrm{H}_{\mathrm{a}}$ akan di tolak. Dalam Nilai Sig. 0,000 hal ini menunjukkan bahwa variabel jam kerja secara parsial berpengaruh terhadap produktivitas karyawan, dengan kata lain variabel jam kerja mempunyai pengaruh signifikan terhadap produktivitas karyawan $^{25}$. Semakin lama jam kerja yg di terapkan, makan semakin tinggi tingkat produktivitas karyawan.

2. Analisis terhadap variabel insentif

Untuk variabel insentif, apabila Sig. 0,00 >0,05 maka $\mathrm{H}_{0}$ diterima dan $\mathrm{H}_{\mathrm{a}}$ pasti akan di tolak. Dan Nilai Sig. 0.847 bahwasanya variabel insentiif secara parsial mengenai produktifitas karyawan tidak memengaruhi, atau variabel insentif tidak

\footnotetext{
${ }^{23}$ WAHYONO.

${ }^{24}$ WAHYONO.

${ }^{25}$ FERNANDO.
} 
mempunyai pengaruh besar mengenai produktivitas karyawan ${ }^{26}$. Denga pemberian insentif atau tidak, tingkat produktifitas karyawan tetap sama.

3. Analisis terhadap variabel kompromi

Untuk variabel kompromi, apabila Sig. 0,00>0,05 maka $\mathrm{H}_{\mathrm{o}}$ diterima dan $\mathrm{H}_{\mathrm{a}}$ ditolak. Nilai Sig. 0.202 variabel kompromi tidak mempunyai pengaruh besar mengenai produktivitas karyawan ${ }^{27}$. Produktivitas tetap pada level yg sama bahkan tanpa kompromi terhadap karyawan.

\subsubsection{Uji F}

Perumusan Hipotesis :

$\mathrm{H}_{\mathrm{o}}$ : variabel jam kerja $\mathrm{X}_{1}$, harga $\mathrm{X}_{2}$ dan lokasi $\mathrm{X}_{3}$ secara simultan tidak berpengaruh terhadap produktivitas karyawan ${ }^{28}$.

$H_{a}$ : variabel jam kerja $X_{1}$, harga $X_{2}$ dan lokasi $X_{3}$ secara simultan berpengaruh terhadap produktivitas karyawan ${ }^{29}$.

Berikut ini adalah hasil perhitungan menggunakan program komputer SPSS 22, yaitu sebagai berikut :

Di bawah ini merupakan hasil dari hitungan penggunaan program pada spss22 adapun hasilnya yaitu sbb :

\section{Tabel 4.15 Hasil Uji F}

\begin{tabular}{|c|c|c|c|c|c|c|}
\hline \multicolumn{7}{|c|}{ Anova $^{\text {a. }}$} \\
\hline & Model & Sum of Squares & $\mathrm{df}$ & Mean Square & $\mathrm{F}$ & Sig. \\
\hline 1 & Regression, & 372.380 & 3 & 124.127 & 17.311 & $.000^{b}$ \\
\hline & Residual, & 688.370 & 96 & 7.171 & & \\
\hline & Total, & 1060.750 & 99 & & & \\
\hline
\end{tabular}

Sumber : Data yang diolah, 2020

Pada pengujian tabel 4.15, bahwa Sig, $0,000<0,05$ hal ini menunjukkan bahwa semua variabel berpengaruh secara simultan. Tingka alfa $(\alpha) 0,05$ dalam kata lain 5\% maka $\mathrm{H}_{\mathrm{o}}$ akan berhasil dan $\mathrm{H}_{\mathrm{a}}$ akan gagal ditolak ${ }^{30}$. Terjadinya penolakan $\mathrm{H}_{\mathrm{o}}$ melalui pembuktian niilai Sig. $(0,000)<$ dari $\alpha$ (alfa $)=0,05$ kita simpulkan semua variabel yakni jam kerja, insentif dan kompromi dengan gaya simultan mempengaruhi produktivitas karyawan Shofa Marwah Group Boyolali ${ }^{31}$.

\subsubsection{Uji Koefisien Determinasi}

\section{Tabel 4.16 Hasil Uji Koefisien Determinasi}

\footnotetext{
${ }^{26}$ FERNANDO.

${ }^{27}$ FERNANDO.

${ }^{28}$ FERNANDO.

${ }^{29}$ FERNANDO.

${ }^{30}$ FERNANDO.

${ }^{31}$ UTAMI.
} 


\begin{tabular}{|c|c|c|c|c|c|}
\hline model & $\mathrm{R}$ & R. Square & $\begin{array}{c}\text { Adjusted. R } \\
\text { Square }\end{array}$ & $\begin{array}{c}\text { Std Error of the } \\
\text { Estimate }\end{array}$ & Durbin-Watson \\
\hline 1 & $.592^{\mathrm{a}}$ & .351 & .331 & 2.678 & 2.474 \\
\hline
\end{tabular}
$\begin{aligned} & \text { a.Predictors: (Constant), KOMPROMI, JAM KERJA, INSENTIF } \\
& \text { b.Dependent Variable: PRODUKTIFITAS }\end{aligned}$

Sumber : Data yang diolah, 2020

Berdasarkan tabel 4.16 dapat dilihat besar nilai $\mathrm{R}_{\text {Square }}$ sebesar 0,351 , hal ini menunjukkan bahwa variabel jam kerja, insentif dan kompromi secara bersama-sama mampu menjelaskan variabel produktivitas karyawan sebesar 35,1\% selebihnya $64,9 \%$ dijelaskan oleh variabel lain seperti pelatihan, motivasi, kepemimpinan dan lain-lain selain variabel-variabel yang diteliti ${ }^{32}$ seperti gaji, pelatihan, dan kepemimpinan.

\section{Kesimpulan}

Setelah melakukan analisis data dan membahas tentang jam kerja, harga, insentif, dan kompromi terhadap produktivitas karyawan Shofa Marwah Group Boyolali maka penulis dapat menggambil kesimpulan:

a. Melalui analisismaka hasil regrresi berganda dengan uji dengan simultan bahwa nilai signifikasi $0,000<0,05$. Hal ini menunjukan bahwa jam kerja, insentif dan kompromi berpengaruh signifikan terhadap produktivitas karyawan di boyolalisehinggah upaya peningkatan kerja pada perusahaan harus meningkatkan jam kerja, insentif dan kompromi. Koefidien nilai determinasi $\left(\mathrm{R}^{2}\right)$ sebanyak 0,351 mempunyai penjelasan dengan jam kerja, insentif dan kompromi secara bersama-sama mampu mempengaruhi variabel produktivitas karyawan sebesar $35,1 \%$ selebihnya $64,9 \%$ dipengaruhi oleh variabel lain yang tidak dimasukkan dalam penelitian ini.

b. Berdasarkan hasil analisis regresi berganda dengan uji t menunjukan nilai sig. $0,000<0,05$ berarti jam kerja berpengaruh signifikan terhadap produktivitas karyawan. Tidak sama seperti penelitian terdahulu yang dilakukan Ryangsyah Putri (2018) yang hasil penelitiannya menjelaskan bahwa jam kerja tidak berpengaruh signifikan terhadap produktivitas karyawan. perusahaan harus menerapkan jam kerja dengan baik.Agar produktivitas karyawan lebih baik terhadap perusahaan tersebut. Upaya yang dapat dilakukan perusahaan untuk menjaga produktivitas karyawan ialah dengan menerapkan jam kerja sesuai dengan kebutuhan hasil kerja..

c. Hasil dari analisis ini yaitu regresi berganda dengan uji t dengan nilai sig. 0,847>0,05 berarti bahwa insentif tidak mempenggaruh produktivitas karyawan. Tidak sama seperti penelitian terdahulu yang dilakukan oleh John Foster Marpaung (2017) hasil penelitiannya menjelaskan bahwa insenif berpengaruh signifikan terhadap produktivitas karyawan. Hasil ini menjelaskan bahwa sebagian karyawan tidak mempertimbangkan insentif untuk meningkatkan produktivitas mereka. Sehingga mereka dapat mencapai hasil pekerjaan dengan baik.

d. Berdasarkan hasil analisis regresi berganda dengan uji t menunjukan nilai sig. 0,202>0,05 berarti bahwa kompromi tidak berpengaruh signifikan terhadap produktivitas karyawan. Penelitian tidak sepaham dengan terdahulu oleh Mohammad Najib Faishol (2016) hasil penelitiannya menjelaskan bahwasanya kompromi berpenggaruh signifikan pada produktivitas karyawan. Hasil ini menjelaskan bahwakaryawan tidak mempertimbangkan kompromi sebagai tolak ukur pada pekerjaannya.

\footnotetext{
${ }^{32}$ UTAMI.
} 


\section{DAFTAR PUSTAKA}

[1] Fernando, Yandhi, "FAKTOR-FAKTOR YANG MEMPENGARUHI PENDAPATAN PEDAGANG KAKI LIMA (STUDI KASUS DI PASAR BESAR KOTA MALANG)",Skripsi Makassar Jurusan Ilmu Ekonomi Feb UNHAS., 2016.

[2] Goleman, Daniel; Boyatzis, Richard; Mckee, Annie, Entrevistado9, Educação Matemática, D A Universidade, D E Mato Grosso, D O Sul, and others, 'MONETER JURNAL AKUNTANSI DAN KEUANGAN VOLUME 7', "Journal of Chemical Information and Modeling", 53.9 (2013),1689-99 <https://doi.org/10.1017/CBO9781107415324.004>.

[3] Merdian, Wili Andri, 'Analisis Pengaruh Kualitas Pelayanan Terhadap Kepuasan Pelanggan (Studi Kasus TIKI, Jl Mantrigawen Lor No 12 Yogyakarta)', Skripsi, 12, 2007, 126

[4] Pertiwi, Nur Rahmantika,"PENGARUH PROGRAM PUNISHMENT DAN REWARD DALAM MENINGKATKAN PRODUKTIVITAS KERJA PEGAWAI MENURUT PERSPEKTIF EKONOMI ISLAM (Studi Pada BPJS Ketenagakerjaan Bandar Lampung)", Jurnal Hospitality Dan Manajemen Jasa, 5 (2017), 390-400

[5] Sugiono, Masyruufah, and Suci Rohayati,"Pengaruh Penggunaan Bahan Ajar E-Book Interaktif, Pemahaman Analisis Transaksi Dan Intensitas Latihan Soal Terhadap Hasil Belajar Siswa Pada Materi Jurnal Khusus Akuntansi Perusahaan Dagang Kelas Xi Smk Negeri 2 Buduran Sidoarjo", Jurnal Pendidikan Akuntansi(JPAK),5.3 (2017), 1-7.

[6] Supriyanto dan Tri Bodroastuti, "Faktor-Faktor Yang Mempengaruhi Produktivitas (Studi Pada Karyawan Bagian Produksi PT Nusantara Building Industries)", 2019,1-14.

[7] Utami, Rumini Tri, 'PENGARUH INSENTIF, MOTIVASI, DAN PRESTASI TERHADAP PRODUKTIVITAS KERJA KARYAWAN DI LAZNAS YATIM MANDIRI', Journal, of Chemical, Information and Modeling, 53.9(2019),1689-99 <https://doi.org/10.1017/CBO9781107415324.004>

[8] Wahyono, Budi, 'ANALISIS FAKTOR-FAKTOR YANG MEMPENGARUHI PENDAPATAN PEDAGANG DI PASAR BANTUL KABUPATEN BANTUL', Jurnal Agribisnis, 11.6 (2017), 183-201 